\title{
Running safety of a railway vehicle in the presence of random track irregularities
}

\begin{abstract}
The paper presents the author's investigations on dynamics of a railway vehicle, especially the effect of various factors on the running safety. The applied simulation methods used for analysis of running safety are in agreement the technical standards UIC 518 and EN 14363. The numerical simulations are performed for non-linear model of railway vehicle ( $a$ passenger car) moving along a tangent track with lateral and vertical geometrical irregularities of random character. The obtained results are used to study how the derailment coefficient is affected by the ride velocity, the parameters of the primary and secondary vehicle suspension, the wear of wheel and rail profiles as well as the track condition. The investigation of running safety is further enhanced by performing the spectral analysis of the dynamical responses of the railway vehicle-track system. It is found that there is a direct relation between the obtained power spectral density (PSD) of the derailment coefficient and the PSD of the lateral and angular wheelset displacements showing the characteristic oscillations due to the wheelset hunting. Finally, the paper presents the results of the statistical analysis of local track geometrical irregularities occurring in the vicinity of the track points where the derailment coefficient attains large values.
\end{abstract}

\section{Introduction}

Running safety is the key element in the analysis of the railway vehicle dynamics and it has to be taken into account in modeling and assessment of the vehicle running behavior. The main objective in assuring the high level of running safety is preventing derailment of a railway vehicle which occurs when the wheels run off the rails. The derailment can be the result of various, sometimes very complicated, conditions which lead to the lost of the lateral guidance, provided by the track during the normal vehicle operation. The four main causes of derailments are: wheel flange climb, gauge widening, rail rollover and track panel shift as it is pointed out in the review [26] by $\mathrm{Wu}$ and Wilson in [8]. The dynamical conditions leading to wheel flange climbing over the rail and the resultant derailment are related to the forces at the wheel/rail contact according to the Nadal criterion proposed in the end of the $19^{\text {th }}$ century [20]. This criterion amended with more contemporary modifications $[4,9,10,17,18,23,25,27,29]$ is still used to assess risk of flange climb derailment in the current regulations $[5,7,19,24]$ applied for testing running safety and approval of railway vehicles. These technical standards include the UIC 518 code [24] and the European standard EN 14363 [5], which are applied in the present study of running safety related to derailment by flange climbing. Investigations of the dynamics of a railway vehicle and the assessment of running safety can be nowadays performed reliably with the aid of the computer simulations [1-3,6,12$17,22,29]$ based on a realistic model of a railway vehicle/track system which includes non-linear wheelset/track geometry constraints as well as nonlinear dependence of the forces at the wheel-rail contact on the creepages [21]. In the present paper, numerical simulations based on a non-linear model of railway vehicle are used to determine the motion of a passenger car along a tangent track with random (stochastic) geometrical irregularities. The main objective of these investigations is comparison how various factors, like ride velocity, suspension parameters and track irregularities, affect the running safety and the ride comfort. The methods used in the technical standards are enhanced by performing the spectral analyses as well as statistical analysis of derailment coefficient and track geometrical irregularities with the objective to established the mutual relation between them.

\section{Railway vehicle-track model}

The performed numerical simulations are done for a railway vehicle moving at constant speed $v$ along a stiff, tangent track. The applied non-linear model of a 
railway vehicle consists of seven rigid bodies: the car body, two bogie frames, and four wheelsets (27 degrees of freedom) [3,12-16]. The primary and secondary vehicle's suspensions are assumed to have linear characteristics. The stiffness constants and damping coefficients as well as masses and inertia moments of the car body, bogies and wheelsets correspond to a passenger car [28]. The forces at the wheel/rail contact are determined with the FASTSIM algorithm developed by Kalker within the simplified non-linear theory of contact [11]. The nominal nonlinear wheel (ORE S1002) and rail (UIC 60) profiles as well as worn profiles of various degree of wear are considered. The model includes the geometrical track irregularities represented by lateral and vertical track deviations $y_{\mathrm{w}}(x), z_{\mathrm{w}}(x)$, variable gauge $2 l_{0}(x)$ and superelevation $h_{\mathrm{w}}(x)$. These parameters are random quantities which vary with position $x$ along the track and are treated as stationary and ergodic stochastic processes. The realizations of the track irregularities are directly included into the equations of motion. These equations are solved numerically to find the coordinates $\mathbf{y}(t)=\left(y_{1}, y_{2}, \ldots, y_{27}\right)$ describing the positions and rotations of all vehicle elements during the vehicle motion over a long track section of the length $L$. The realizations of the track irregularities (see Fig. 1) applied in simulations, i.e., $y_{\mathrm{w}}(x), z_{\mathrm{w}}(x), 2 l_{0}(x), h_{\mathrm{w}}(x)$ have the length of $4000 \mathrm{~m}$ and their respective standard deviations are equal to $\sigma_{y w}=0.003 \mathrm{~m}, \quad \sigma_{z w}=0.0035 \mathrm{~m}$, $\sigma_{2 l}=0.0011 \mathrm{~m}, \sigma_{h_{w}}=0.0010 \mathrm{rad}$; the corresponding power spectral densities are shown in $[3,14]$
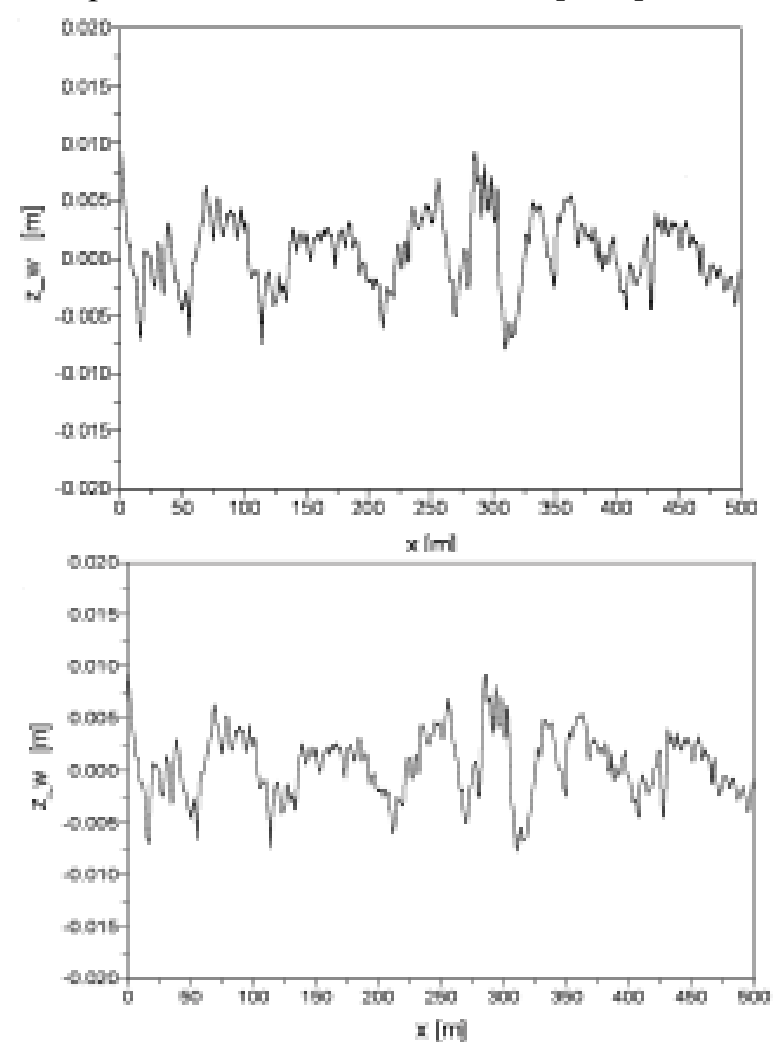

Fig. 1. Lateral $\left(y_{\mathrm{w}}\right)$ and vertical $\left(z_{\mathrm{w}}\right)$ track irregularities used in the simulations (data for the initial $500 \mathrm{~m}$ track section are shown)

\section{Assesment of running safety}

As it has already been mentioned in the introduction, there are several causes of the derailment of a railway vehicle. One of the main scenarios of derailment is realised when during the vehicle motion a large lateral force acting on a wheelset leads to the wheel flange contact with the rail - as a result flange climbs up the rail rapidly (especially after the flange angle attains its maximum value) and the wheelset derails. The occurrence of the flange climb derailment is related to the ratio $Y / Q$ of the lateral to vertical force components at the wheel-rail contact, see Fig.2. This force ratio is usually called the derailment coefficient.

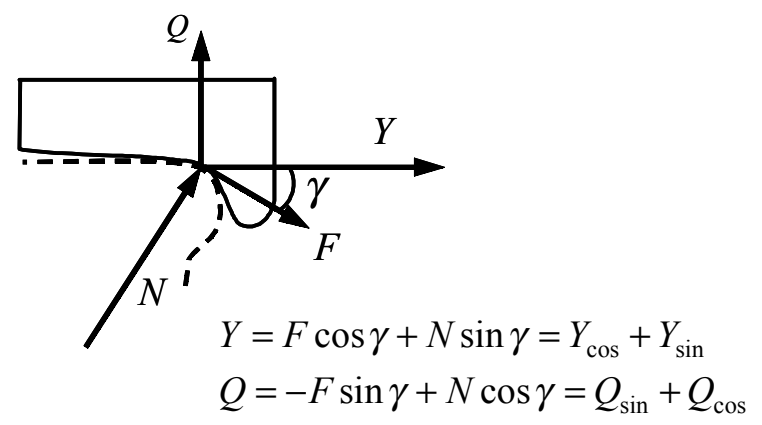

Fig.2. Force components at a wheel/rail contact: lateral $(Y)$ and vertical $(Q)$, normal force $(N)$ and lateral rolling-friction force $(F)$.

The condition of the saturated friction force (depending on the friction coefficient $\mu$ ) leads to the Nadal criterion [24]:

$$
\left|\frac{Y}{Q}\right|<\frac{\operatorname{tg} \delta-\mu}{1+\mu \operatorname{tg} \delta}
$$

which gives the maximum value of $Y / Q$ calculated for the maximum flange contact angle $\delta$. This criterion is easy to implement and it is widely used for assessment of the safety against derailment. In particular, the Nadal criterion - in a modified form - is applied to assess the risk of flange climb derailment in the UIC 518 code [24] and European standard EN14363 [5] used for testing and approval of railway vehicles. The main modification adopted in these two standards is the requirement that the ratio $Y / Q$ exceeds the assumed critical value of 0.8 over a $2 \mathrm{~m}$ track interval. This is done because derailment can actually take place only if the ratio $Y$ / $Q$ exceeds the limit value for a sufficiently long time interval as it was concluded in the studies of Japanese National Railways (JNR) and General Motors Electromotive 
Division (EMD). The condition of minimum $Y / Q$ duration is also imposed in other regulations regarding the running safety that are used for certification and testing of railway vehicles by Association of American RailRoads (AAR) [19] and the Federal Railroad Administration (FRA), U.S.[7]. The risk of wheel climb derailment also strongly depends on the wheelset angle of attack $\psi$ so that the actual derailment occurs at the original Nadal's value of $Y / Q$ only for sufficiently large $\psi$ [4]. Therefore, Elkins and $\mathrm{Wu}$ [4] proposed the increased $Y / Q$ limit value for angle of attack $\psi$ smaller than 5 mrad. This conclusion was confirmed in the report [27] which proposed bi-parameter expressions for the flange climb distance as a function of both $\psi$ and $Y / Q$. Another extension of the Nadal criterion is the Weinstock criterion [25] which sets a maximum value for the sum of the $Y / Q$ ratios for both wheels on the same axle instead the single ratio $Y / Q$ for flanging wheel only. It is less conservative and regarded to be more accurate than the Nadal criterion, but it is not so widely applied.

The assessment of safety against derailment in the present work is performed according to the UIC Code 518 and the EN 14363 standards. In the first step, the ratio $Y / Q$ obtained from simulations is averaged at each track point $x$ over the surrounding $2 \mathrm{~m}$ track section (window) $[x-1 \mathrm{~m}, x+1 \mathrm{~m}]$. This is done to satisfy the discussed requirement of minimum flange climb distance necessary for derailment. Thus, the running average $(Y / Q)_{2 \mathrm{~m}}$ is calculated.
Next, the 99.85 percentile value $\left.(Y / Q)_{2 m}\right|_{0.9985}$ is found following the UIC recommendations. The obtained values $\left.(Y / Q)_{2 m}\right|_{0.9985}$ have been compared to the limit value 0.8 adopted in the standards [5,24]. This method of assessment of safety against derailment - described in more detail in $[13,15]$ - is presented schematically in Fig.3.

\section{Running safety - effect of speed, suspension and track irregularities}

On the basis of the simulation studies [12-15], it can be concluded that the values of $\left.(Y / Q)_{2 \mathrm{~m}}\right|_{0.9985}$ :

- grow with the increase of the ride velocity but they do not exceed the limit value 0.8 for the investigated speeds in the interval from 80 to $200 \mathrm{~km} / \mathrm{h}$ (see Table 1 ),

- grow with the increasing amplitude of the lateral irregularities, while the effect of the vertical irregularities is practically negligible (see Table 2),

- are practically identical for the front and rear bogies, and significantly larger for the leading wheelset than for the trailing one.

The effect of various suspension parameters on safety against derailment has been investigated in the work [12] and the results are summarized in Table 3.

The 99.85 percentile value $\left.(Y / Q)_{2 m}\right|_{0.9985}$ for various ride velocities $v$

Table 1

\begin{tabular}{|l|l|c|c|c|c|}
\hline bogie & wheelset & $v=80 \mathrm{~km} / \mathrm{h}$ & $v=120 \mathrm{~km} / \mathrm{h}$ & $v=160 \mathrm{~km} / \mathrm{h}$ & $v=200 \mathrm{~km} / \mathrm{h}$ \\
\hline \multirow{2}{*}{ front/rear } & leading & 0.266 & 0.321 & 0.411 & 0.650 \\
\cline { 2 - 6 } & trailing & 0.105 & 0.134 & 0.236 & 0.482 \\
\hline
\end{tabular}

Table 2

The 99.85 percentile value $\left.(Y / Q)_{2 m}\right|_{0.9985}$ for various amplitudes of the lateral $y_{w}$ and vertical $z_{w}$ track irregularities; ride velocity $v=160 \mathrm{~km} / \mathrm{h}$

\begin{tabular}{|l|l|c|c|c|c|c|}
\hline \multirow{2}{*}{ bogie } & $\begin{array}{l}\text { wheel- } \\
\text { set }\end{array}$ & $\begin{array}{c}y_{w, \exp }, z_{w, \exp } \\
\text { (experimental } \\
\text { realization) }\end{array}$ & $\begin{array}{c}y_{w}=2 y_{w, \exp } \\
z_{w}=z_{w, \exp }\end{array}$ & $\begin{array}{l}y_{w}=3 y_{w, \exp } \\
z_{w}=z_{w, \exp }\end{array}$ & $\begin{array}{c}z_{w}=2 z_{w, \exp } \\
y_{w}=y_{w, \exp }\end{array}$ & $\begin{array}{c}z_{w}=3 z_{w, \exp } \\
y_{w}=y_{w, \exp }\end{array}$ \\
\hline \multirow{2}{*}{ front/ rear } & leading & 0.411 & 0.538 & 0.670 & 0.414 & 0.418 \\
\cline { 2 - 7 } & trailing & 0.236 & 0.377 & 0.447 & 0.237 & 0.237 \\
\hline
\end{tabular}

\begin{tabular}{|c|c|c|c|}
\hline$Y / Q \rightarrow$ & $(Y / Q)_{2 m} \rightarrow$ & $F(Y / Q)_{2 m} \rightarrow$ & $\left.(Y / Q)_{2 m}\right|_{0.9985} \leq 0.8$ \\
simulation results & $\begin{array}{c}\text { running average with } \\
\text { the 2m window }\end{array}$ & $\begin{array}{c}\text { probability distribution } \\
\text { function }\end{array}$ & 99.85 percentile value \\
\hline
\end{tabular}

Fig.3. Evaluation of safety against derailment according to UIC Code 518 [12] the illustration of its consecutive steps based on the simulation results. 
Values of $\left.(Y / Q)_{2 m}\right|_{0.9985}$ for various values of the suspension stiffness and damping parameters: $c_{n y}, k_{n z}, c_{z z}$ and $k_{z y} ; v=160 \mathrm{~km} / \mathrm{h}$

\begin{tabular}{|c|c|c|c|c|}
\hline bogie & wheelset & $c_{n y}=0 \mathrm{kN} \mathrm{s} / \mathrm{m}$ & $c_{n y}=10 \mathrm{kN} \mathrm{s} / \mathrm{m}$ & $\begin{array}{l}c_{n y}=20 \mathrm{kN} \mathrm{s} / \mathrm{m} \\
(\text { nominal value) }\end{array}$ \\
\hline \multirow{2}{*}{ front/rear } & leading & 0.444 & 0.426 & 0.411 \\
\hline & trailing & 0.257 & 0.236 & 0.236 \\
\hline bogie & wheelset & $k_{n z}=200 \mathrm{kN} / \mathrm{m}$ & $\begin{array}{l}k_{n z}=414 \mathrm{kN} / \mathrm{m} \\
(\text { nominal value) }\end{array}$ & $k_{n z}=600 \mathrm{kN} / \mathrm{m}$ \\
\hline \multirow[t]{2}{*}{ front/rear } & leading & 0.413 & 0.411 & 0.446 \\
\hline & trailing & 0.234 & 0.236 & 0.212 \\
\hline bogie & wheelset & $c_{z z}=0 \mathrm{kN} \mathrm{s} / \mathrm{m}$ & $\begin{array}{c}c_{z z}=85 \mathrm{kN} \mathrm{s} / \mathrm{m} \\
(\text { nominal value) }\end{array}$ & $c_{z z}=200 \mathrm{kN} \mathrm{s} / \mathrm{m}$ \\
\hline \multirow{2}{*}{ front/rear } & leading & 0.550 & 0.411 & 0.409 \\
\hline & trailing & 0.509 & 0.236 & 0.136 \\
\hline bogie & wheelset & $k_{z y}=1000 \mathrm{kN} / \mathrm{m}$ & $\begin{array}{l}k_{z y}=1962 \mathrm{kN} / \mathrm{m} \\
(\text { nominal value) }\end{array}$ & $k_{z y}=4000 \mathrm{kN} / \mathrm{m}$ \\
\hline \multirow{2}{*}{ front/rear } & leading & 0.400 & 0.411 & 0.411 \\
\hline & trailing & 0.307 & 0.236 & 0.181 \\
\hline
\end{tabular}

The obtained results show that the changes of stiffness constants and damping coefficients usually affect the values of $\left.(Y / Q)_{2 \mathrm{~m}}\right|_{0.9985}$ weakly, especially for the leading wheelset, while the effect for the trailing wheelset is slightly stronger. The important exception from this general rule is the breakdown of the damper in the vertical primary suspension $\left(c_{z z}=0\right)$ which leads to a large increase of $\left.(Y / Q)_{2 \mathrm{~m}}\right|_{0.9985}$ for all wheelsets even to doubling this value for the trailing wheelsets). On the other hand, the change of the damping coefficient in the lateral secondary suspension (even $c_{n y}=0$ ) modifies $\left.(Y / Q)_{2 \mathrm{~m}}\right|_{0.9985}$ very slighty, by less than $10 \%$.

Based on the obtained results presented in tables $1-3$, it can be concluded that the values of $\left.(Y / Q)_{2 \mathrm{~m}}\right|_{0.9985}$ are practically identical for the front and rear bogies, and significantly larger for the leading wheelset than for the trailing one. The only exception is the case of $c_{z z}=0$ when the values of $\left.(Y / Q)_{2 \mathrm{~m}}\right|_{0.9985}$ are only slightly larger for the leading wheelset than for the trailing one.

\section{Effect of wheel and rail profile wear and track condition}

Several further simulation tests have been done with objective is to study the effect of factors on the running safety defined with the "safety against derailment" criterion discussed in the previous section.
The following factors have been investigated:

- different rail and wheel profiles (nominal and worn),

- track sections with different quality (QN1, QN2),

- ride velocity (for every case of considered profiles and track sections).

In the performed simulations three different pairs of wheel and rail profiles have been applied: a pair of the nominal S1002 (wheel) and UIC60 (rail) profiles and two pairs of the worn S1002 and UIC60 profiles - with medium and strong degree of wear. The applied nominal and worn wheel and rail profiles are shown in Ref.[3].

Simulation tests used in the running safety studies are done for two sections of straight track with different quality: QN1, QN2. The respective standard deviations of track irregularities are given in the Table 4. The standard deviations are larger for the QN2 section than for the QN1 section for every component of track irregularities. In simulation tests, the values of $Y / Q$ for leading and trailing wheelsets of front and rear boogies have been obtained for both track sections, three pairs of wheel/rail profiles and several ride velocities $v$. For each case the values $\left.(Y / Q)_{2 m}\right|_{0.9985}$ are then calculated from the simulation results $Y / Q$ as explained in Section 3. The dependence of the obtained $\left.(Y / Q)_{2 m}\right|_{0.9985}$ on the wear of wheel and rail profiles, track quality, and ride velocity $v$, is analyzed in the cumulative plot 
shown in Fig.3, for leading wheelset.

These results show that the effect of the considered factors on the running safety is not always easily predictable and interplay between different factors can take place. First, it is found that the value of $\left.(Y / Q)_{2 m}\right|_{0.9985}$ grows with $v$ for most investigated running conditions. It confirms the well-known fact that the ride velocity $v$ is an essential factor in running safety which decreases with the increase of $v$.

Standard deviations of track geometric deviations of alignment $y_{w}$, level $z_{w}$, gauge $2 l$ and cant $h_{w}$ for the QN1 and QN2 track sections used in simulations
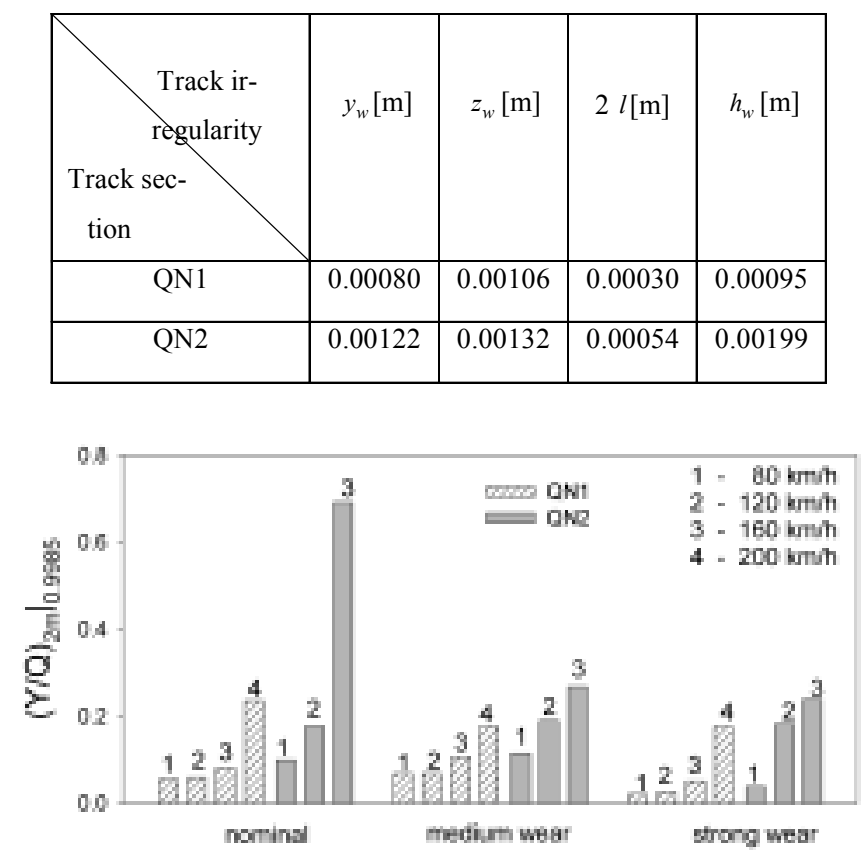

Fig 3. The 99.85 percentile value $\left.(Y / Q)_{2 m}\right|_{0.9985}$ for the leading wheelset of front/rear boogie for various rail and wheel profiles, track conditions (QN1 and QN2) and ride velocities $v$.

The track quality is another key factor which affects the running safety. For all considered wheel/rail profiles and ride velocities, the obtained values of $\left.(Y / Q)_{2 m}\right|_{0.9985}$ are usually much larger for the QN2 track section than for the QN1 section and the effect of track quality becomes stronger for high ride velocities.

The influence of the wheel and rail profile wear is more complex. It is found on the basis of simulations that in most cases the ratio $Y / Q$ tends to decrease for strongly worn wheel and rail profiles in comparison to nominal profiles. It is the result of a better match between the worn wheel and rail profiles than nominal ones. The dependence on the profile wear is more pronounced for higher ride velocities and track sections with poorer quality (e.g. QN2).

In conclusion, the running safety of railway vehicle is strongly affected by both track quality and degree of wheel/rail profile wear. However, this effect is diverse for different wheelsets and ride velocities.

\section{Spectral analysis of derailment coefficient}

The lateral (Y) and vertical (Q) forces at wheel/rail contact in the simulation are the system's dynamic responses to the perturbation induced by the random track irregularities. Thus, the ratio $Y / Q$ can be treated as a stationary and ergodic stochastic process which contains component oscillations with various frequencies and random phases. Its spectral composition is analyzed with the power spectral density (PSD) determined numerically from the signal $Y / Q$. This is done with Welch's modified periodogram method in which a long track section $(0, L)$ is split up into partly overlapping segments $\left(L_{\mathrm{o}}^{(m)}, L_{\mathrm{k}}^{(m)}\right)$ of the same length $\Delta L=L_{\mathrm{k}}^{(m)}-L_{\mathrm{o}}^{(m)}$. The Fourier transform of a function $y(x)=y(v t)$ is then computed for each of the $M$ segments $\left(L_{\mathrm{o}}^{(m)}, L_{\mathrm{k}}^{(m)}\right)$ and a given spatial frequency $f$ :

$$
S_{y}^{(m)}(f)=\frac{2}{\Delta L}\left|\int_{L_{\mathrm{o}}^{(m)}}^{L_{\mathrm{k}}^{(m)}} y(x) e^{i 2 \pi f x} d x\right|^{2},
$$

where $m=1,2, \ldots, M$. The estimator of the power spectral density $S_{y}(f)$ for the whole track section is found as the following arithmetic mean

$$
S_{y}(f)=\frac{1}{M} \sum_{m=1}^{M} S_{y}^{(m)}(f)
$$

The numerical PSD calculations based on the above method are performed with the aid the pspect procedure from the SCILAB package.
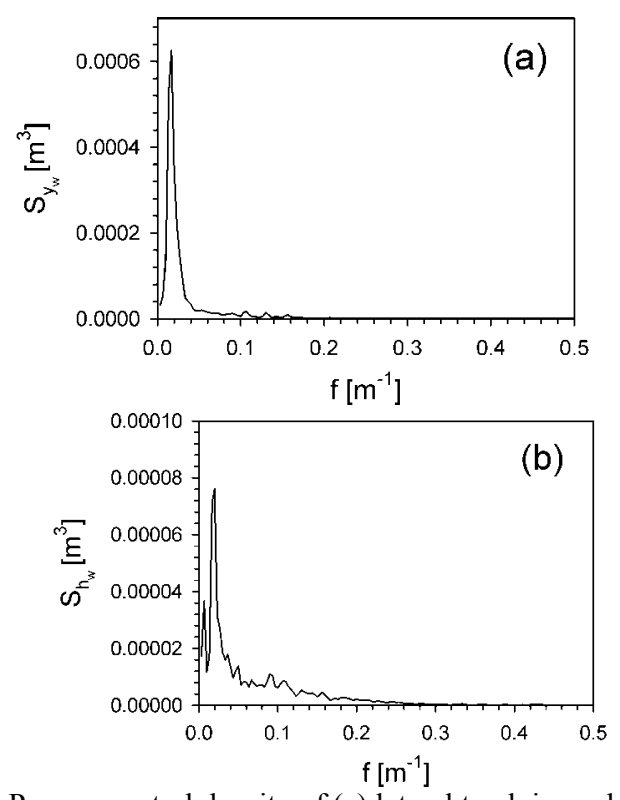

Fig.4. Power spectral density of (a) lateral track irregularities $y_{w}$ and (b) local superelevation $h_{w}$ 
The investigated PSD, $S_{Y / Q}(f)$ of the derailment coefficient has been computed from $Y / Q$ obtained in the simulations over a $4000 \mathrm{~m}$ track section. The PSD of the track irregularities (lateral and superelevation) are shown in Fig. 4. It is found that the obtained PSD are nearly identical for the leading wheelsets of the front and rear bogie. The same is true for the two trailing wheelsets. However, the spectral distribution of $S_{Y / Q}(f)$ is significantly different for the leading wheelset than for the trailing one. The PSD of $Y / Q$ in the leading wheelset has three main peaks with maxima at frequencies $f_{1} \approx 0.01 \mathrm{~m}^{-1}, f_{2} \approx 0.11 \mathrm{~m}^{-1}$, and $f_{3} \approx 2 f_{2} \approx 0.22 \mathrm{~m}^{-1} ;$ see Fig. 5. In the case of the trailing wheelset, the function $S_{Y / Q}(f)$ is concentrated within the spatial frequency interval $0.06 \mathrm{~m}^{-1} \leq f \leq 0.18 \mathrm{~m}^{-1}$ and it attains the maximum for $f_{2} \approx 0.11 \mathrm{~m}^{-1}$; see Fig. 5 . The peak positions at spatial frequencies $f_{1}, f_{2}, f_{3}$ do not change when the ride velocity increases or if the amplitudes of track irregularities become larger. However, the magnitude of $S_{Y / Q}(f)$ grows with increasing ride velocity $v$ in the whole range of the spatial frequencies $f$, particularly strongly near $f=f_{2}$. This corresponds to the increase of standard deviation $\sigma_{Y / Q}$ of $Y / Q$ (see Table 5) which can be expressed with the integral of the function $S_{Y / Q}(f)$ over $f$. Similarly as the percentile values $\left.(Y / Q)_{2 m}\right|_{0.9985}$, the standard deviation $\sigma_{Y / Q}$ is larger for the leading wheelset than for the trailing one despite the fact that the peak values of $S_{Y / Q}(f)$ at $f=f_{2}$ are significantly larger for the trailing wheelset.

By comparing the density $S_{Y / Q}(f)$ with the power spectral densities of track irregularities, it is found [18] that the $Y / Q$ component waves with the spatial frequencies at $f=f_{1}$ are induced by the dominating component waves in the lateral and vertical track irregularities $y_{\mathrm{w}}, z_{\mathrm{w}}$ which disturb the railway vehicle motion. The $Y / Q$ PSD peak at $f=f_{2}$ originates from wheelset hunting. This conclusion is reached by comparing the obtained $S_{Y / Q}(f)$ with the PSD of the lateral displacement $y-y_{\mathrm{w}}$ and yaw
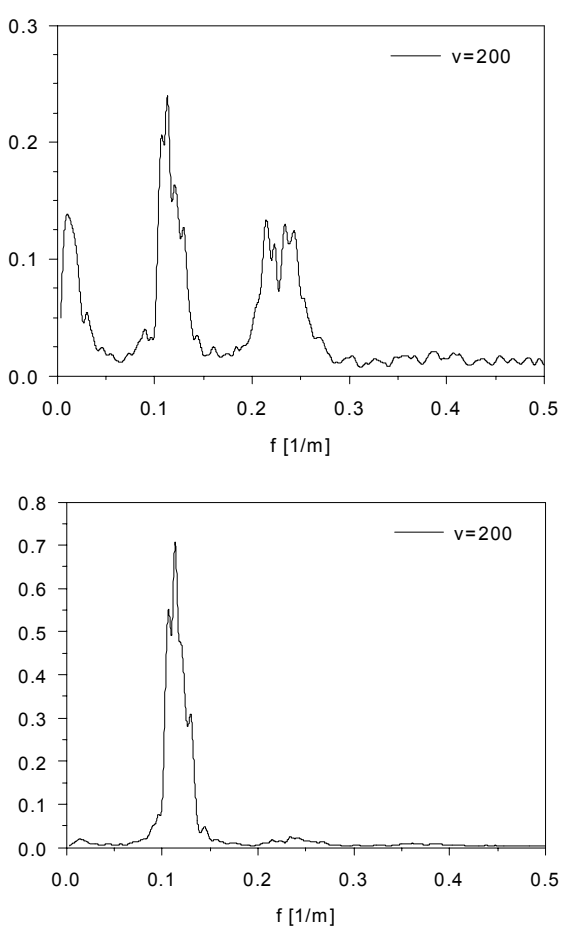

Fig. 5. Power spectral density of $\mathrm{Y} / \mathrm{Q}$ for the (a) leading and (b) trailing wheelsets (left wheel) of the rear boogie; $v=200 \mathrm{~km} / \mathrm{h}$.

rotation angle $\psi-\psi_{\mathrm{w}}$ of a wheelset with the respect to the track [14].

The third peak $f_{3}$ corresponds to the doubled frequency $f_{2}$. The origin of the peak at $f=f_{3} \approx 2 f_{2}$, is investigated by analyzing the components of the lateral contact force $Y=Y_{\text {cos }}+Y_{\text {sin }}$ given by Eq.(1), see Fig.1. First, it is found that while wheelset displacements $y^{*}=y-y_{\mathrm{w}}$ and $\psi^{*}=\psi-\psi_{\mathrm{w}}$ have quasisinusoidal dependence on time $t$ during the wheelset hunting, the time dependence of the flange angle $\gamma$ at the point of the wheel/rail contact is not given by a similar smooth function of $t$, though the function $\gamma(t)$ has the same periodicity as $y^{*}(t)$ and $\psi^{*}(t)$. This is related to the non-linear dependence of $\gamma=\gamma\left(y^{*}, \psi^{*}\right)$ which results in large flange angle $\gamma$ at maximum lateral displacements $y^{*}$ of the wheelset during hunting. This non-linearity generates secondharmonic terms in the function $\gamma(t)$ and, consequently, in the forces components $Y_{\cos }=F \cos \gamma$, $Y_{\text {sin }}=N \sin \gamma$. This leads to peaks at $f=2 f_{2}$ in the power spectral densities of the derailment coefficient

Standard deviation $\sigma$ of $Y / Q$ for leading and trailing wheelsets (left wheel) of the front boogie for various ride velocities $v$

\begin{tabular}{|c|c|c|c|c|}
\hline wheelset & $\nu=80 \mathrm{~km} / \mathrm{h}$ & $\nu=120 \mathrm{~km} / \mathrm{h}$ & $\nu=160 \mathrm{~km} / \mathrm{h}$ & $\nu=200 \mathrm{~km} / \mathrm{h}$ \\
\hline leading & 0.036 & 0.050 & 0.076 & 0.160 \\
\hline trailing & 0.018 & 0.030 & 0.057 & 0.145 \\
\hline
\end{tabular}


of $Y / Q$. Thus the occurrence of the peak at the doubled hunting frequency in the PSD of $Y / Q$ is shown to be the result of the strongly non-linear dependence of the wheel flange angle at the wheel/rail contact point on the wheelset displacement with respect to the track. The important additional factor that facilitates the emergence of the $Y / Q$ oscillations with double hunting frequency the leading wheelset is the significant difference between the oscillation phases of the two components $(F \cos \gamma, N \sin \gamma)$ of lateral contact force $Y$ : one proportional to the normal load $N$ and the other - to transverse tangent contact force $F$, dependent on creepages at the wheel/rail contact. The difference between the phases of the two lateral contact force components is found to be much smaller for the trailing wheelset which explains the absence of the $f=2 f_{2}$ peak in the corresponding PSD of $Y / Q$. Such phase differences between the oscillations of the two contact force components are shown to be closely related to the phase shift between the oscillations of the lateral wheelset displacement (with respect to the track) and of the yaw angle (angle of attack) due to wheelset hunting. This phase shift is found to be significantly smaller for the leading wheelset than for the trailing one when the railway vehicle negotiates geometrical irregularities during its motion along the track.

It is also found that the spectral distribution of the derailment coefficient depends strongly on the lateral stiffness and vertical damping in the primary suspension, as well as on track condition (geometrical irregularities) however its characteristic shape with one or three peaks remains unchanged. The magnitude of $S_{Y / Q}(f)$ grows at each of three peak frequencies $f=f_{1}, f_{2}, f_{3}$ if the lateral stiffness in the primary suspension is reduced; see Fig. 6. The failure of the vertical damper in the primary suspension leads to a three-fold increase of the peak value $S_{Y / Q}(f)$ at $f=f_{2}$ while other PSD peaks are much less affected. It has been shown [14] that the characteristic threepeak structure of $S_{Y / Q}(f)$ exists for the leading wheelset and the third peak is absent for the trailing wheelset for track sections with significantly different track irregularities.

a)

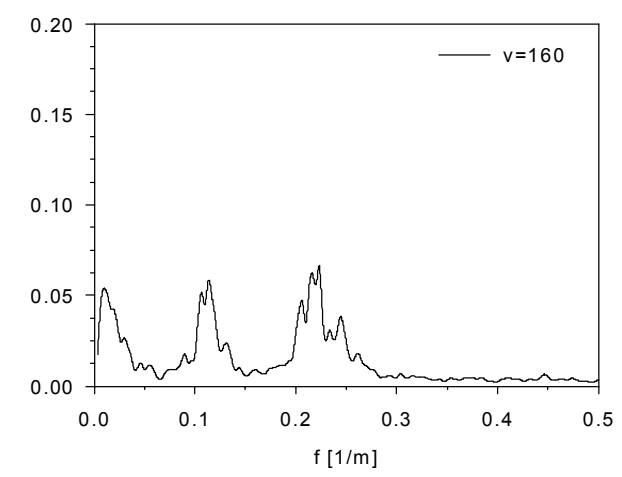

b)

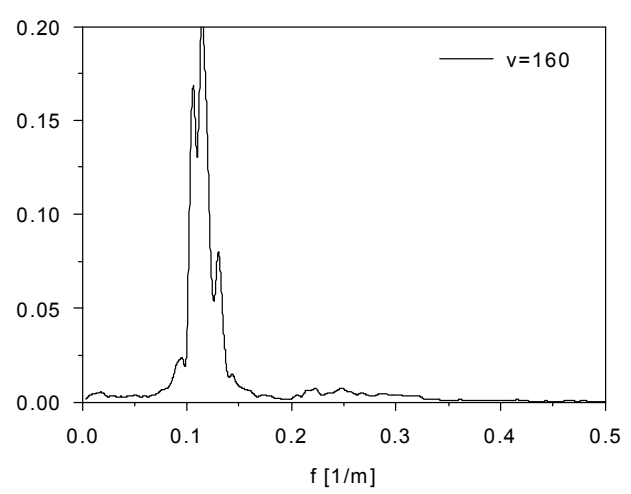

c)

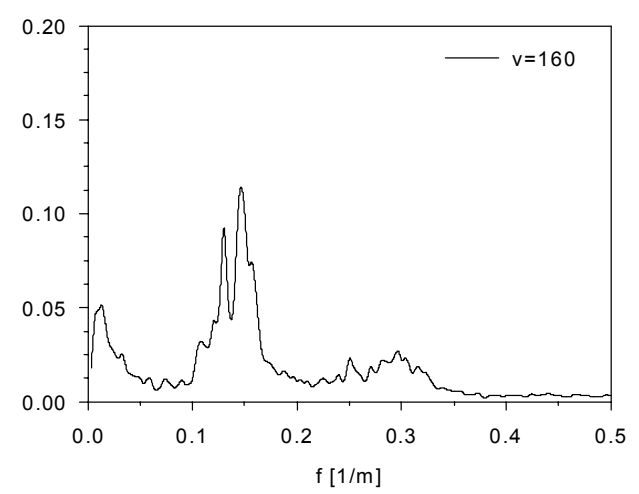

d)

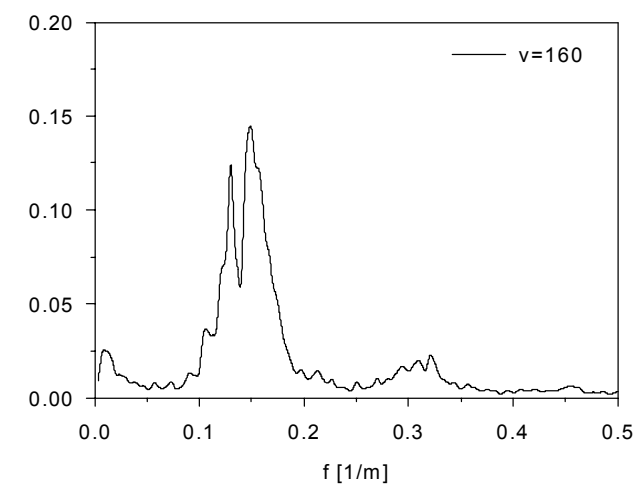

Fig. 6. Power spectral density of $Y / Q$ the $(a, c)$ leading and $(b, d)$ trailing wheelsets (left wheel) of the front boogie for modified parameters of the primary suspension: $(a, b)$ lateral stiffness constant (per wheelset) $1000 \mathrm{kN} / \mathrm{m}$ (nominal value $1962 \mathrm{kN} / \mathrm{m}$ ), (c,d) zero vertical damping (damper failure).

The relation of wheelset hunting to track condition is analyzed by simulations of the vehicle motion for track irregularities with oscillations from various spatial frequency ranges obtained by applying a band-pass filter. It is concluded that the wheelset hunting and the resultant peak of $S_{Y / Q}(f)$ at $f=f_{2}$ are induced by the lateral track irregularities with spatial frequencies from the interval $0.05 \mathrm{~m}^{-1}<f<0.15 \mathrm{~m}^{-1}$ including hunting frequency $f_{2}$. This conclusion is not so obvious (as it may seem so at first) since the PSD of the applied lateral track irregularities is concentrated almost entirely within the interval $0<f<0.05 \mathrm{~m}^{-1}$; see Fig.4. This means that relatively very small oscillatory component of track irregularities is responsible for a major effect in vehicle dynamics (i.e. wheelset hunting) and thus 
leads to large component in the ratio of $Y / Q$ determining the running safety. The oscillations of $Y / Q$ related to hunting manifest in strong though narrow peaks of the derailment coefficient $Y / Q$ with instantaneous values often exceeding the Nadal limit (thought becoming smaller than 0.8 after averaging with $2 \mathrm{~m}$ window according to UIC 518 code.

\section{Safety against derailment - statistical analysis of local track irregularities}

Track geometric irregularities are a major factor which leads to large vales of the derailment coefficient $Y / Q$ during the motion of a railway vehicle. The relation between $Y / Q$ and local track condition has been studied with a statistical analysis of local track irregularities performed for many peaks of $Y / Q$ obtained in simulations of vehicle motion on a long section of tangent track with random irregularities. This analysis is done by considering the track irregularities, e.g. the lateral irregularities $y_{w}(x)=y_{w}\left(x_{\text {peak }}^{(k)}+u\right)$ in the vicinity of different $M$ track points $x=x_{\text {peak }}^{(k)}$, where the high peaks of $|Y / Q|$, exceeding 1.3 , occur. The statistical average

$$
y_{w}^{\mathrm{av}}(u)=\frac{1}{M} \sum_{k=1}^{M} y_{w}\left(x_{\text {peak }}^{(k)}+u\right)
$$

describes a typical dependence of $y_{w}$ as a function of the distance $u$ from the track point at which the $Y / Q$ peaks are present. In a similar way, the statistically averaged values at local superelevation $h_{w}^{\text {av }}$, and of the lateral wheelset displacement $y_{1}^{\mathrm{av}}(u)-y_{w}^{\mathrm{av}}(u)$ with respect to the track are determined. The obtained values of $y_{w}^{\mathrm{av}}(u), h_{w}^{\mathrm{av}}(u)$ and $y_{1}^{\mathrm{av}}(u)-y_{w}^{\mathrm{av}}(u)$ are shown in Fig.7.

It is found that within short track intervals, about $30 \mathrm{~m}$ long, directly before the $Y / Q$ peaks, both lateral irregularity and local superelevation contain dominant oscillatory components of spatial frequencies close to the spatial frequency of wheelset hunting, equal to $9 \mathrm{~m}$ in the performed simulations. Thus, it is concluded that local increase of oscillations of lateral track irregularities $y_{w}$ and local superelevation $h_{w}$, with wavelenghts close to hunting wavelenght, is responsible for the occurrence of the $Y / Q$ peaks and consequently, for the increased risk of derailment.

This conclusion regarding the local track condition is in agreement with the previous results of the spectral analysis of the ratio $Y / Q$ obtained for track geometrical irregularities modified with band- pass filter for chosen spatial frequency bands.

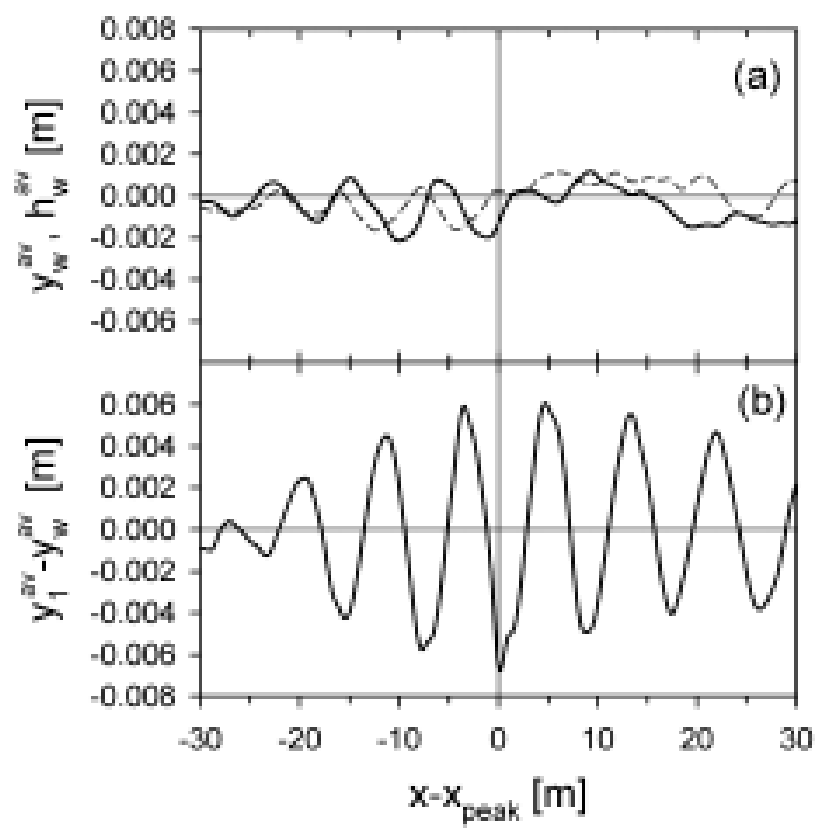

Fig.7. The statistically averaged values: $y_{w}^{\mathrm{av}}, h_{w}^{\mathrm{av}}$ and $y_{1}^{\mathrm{av}}(u)-y_{w}^{\mathrm{av}}(u) \quad$ of lateral track irregularities, local superelevation and lateral displacement (with respect to the track) of leading wheelset (in front bogie) in the vicinity of track points where the maximum values $|Y / Q| \geq 1.3$ occur.

\section{Conclusions}

The results of reported investigations based on numerical simulations for a non linear model of railway vehicle show how the running safety is affected by various factors, related to the vehicle build and track conditions. The risk of derailment is assessed according to current UIC and European technical standards [5,24] with the aid of the wheel/rail contact force ratio $Y / Q$. It is found to be strongly influenced both by ride velocity and lateral track irregularities, while changes of stiffness and damping coefficients of the vehicle suspension modify the derailment coefficient $Y / Q$ less significantly, except for the case of the breakdown of the damper in the vertical primary suspension. Another important factor which affects the safety against derailment is the wear of wheel and rail profiles. The obtained simulation results shown in that the $Y / Q$ value decreases for worn profiles which emphasizes the role of matching the wheel/rail profiles in the process of railway vehicle operation.

The spectral analysis of the derailment coefficient $Y / Q$ allows for enhanced investigation of the running safety in relation to the vehicle dynamical behavior and the track condition. The power spectral density of $Y / Q$ have been found to contain up to three main peaks, the first of which directly corresponds to the spatial frequency of the dominating oscillatory contributions in the lateral and vertical track geometrical irregularities. The other two peaks 
in the PSD $S_{Y / Q}(f)$ result from the wheelset hunting and they are concentrated around the spatial frequency of hunting $f_{2}$ and at its double $2 f_{2}$. This frequency doubling is obtained only for the leading wheelsets and it is shown to be the result of the strongly non-linear dependence of the wheel flange angle at the wheel/rail contact point on the wheelset displacement. The spectral distribution of the derailment coefficient is also shown to depend strongly on the lateral stiffness and vertical damping in the primary suspension.

It is also found, by applying a band-pass filter to track irregularities prior to simulations, that the wheelset hunting and the resultant peaks emerging in the PSD of $Y / Q$ (at $f=f_{2}, 2 f_{2}$ ) are induced by a very small fraction of the total track irregularities which corresponds to a spatial frequency range centered at the hunting frequency. This conclusion is confirmed by a statistical analysis applied to track geometrical irregularities in the vicinity of track points where large values of derailment coefficient $Y / Q$ occur. It is found that lateral track irregularities and superelevation on short track sections before such points include large local oscillations with wavelengths close the wavelength of wheelset hunting which lead to the occurrence of local extrema of $Y / Q$.

\section{References}

[1] Chudzikiewicz, A.: Simulation of Rail Vehicle Dynamics in MATLAB Environment, Vehicle System Dynamics, Vol. 33, 2000, pp.107-119

[2] Chudzikiewicz A., Droździel J., Sowiński B.: The influence of wheel and rail rolling surfaces wear on railway vehicle dynamics Proceedings of the CSME Forum 2004, Univ. of Western, Ontario, Canada, p. 945

[3] Droździel J., Kardas-Cinal E., Sowiński B.: Railway vehicle safety assessment affected by wheel and rail wear, Proceedings of the $11^{\text {th }}$ Mini Conference on "Vehicle System Dynamics, Identification and Anomalies", VSDIA 2010, Budapest, Hungary, 2010 (in press)

[4] Elkins J., Wu H.: New criteria for flange climb derailment, Proceedings of the ASME/IEEE Joint Railroad Conference, 2000, pp.1-7

[5] EN 14363, Railway applications - Testing for the acceptance of running characteristics of railway vehicles - Testing of running behaviour and stationary tests, European Committee For Standardization, 2005

[6] Evans J., Berg M.: Challenges in simulation of rail vehicle dynamics, Vehicle System Dynamics, Vol. 47 (8), 2009, pp. 1023-1048

[7] Federal Railroad Administration: Track Safety Standards, Part 213, Subpart G., 1998

[8] Iwnicki S. (ed.): Handbook of Railway Vehicle Dynamics, CRC Press Inc., 2006
[9] Ishida, H., Matsuo, M.: Safety Criteria for Evaluation of Railway Vehicle Derailment", Quarterly Report of RTRI, Vol. 40, No.1, 1999, pp.18-25

[10] Ishida H. et al.: Safety Assessment for Flange Climb Derailment of Trains Running at Low Speeds on Sharp Curves", Quarterly Report of RTRI, Vol. 47 (2), pp. 65-71, 2006

[11] Kalker J.J.: A fast algorithm for the simplified theory of rolling contact, Vehicle System Dynamics Vol.11, 1-3, 1982

[12] Kardas-Cinal E., Zboiński K.: Investigation of Safety of a Railway Vehicle in the Presence of Random Track Irregularities, Proceedings of the $10^{\text {th }}$ Mini Conference on "Vehicle System Dynamics, Identification and Anomalies”, Budapest, Hungary, 2006, pp.169-176.

[13] Kardas-Cinal E.: Symulacyjna analiza kryteriów bezpieczeństwa jazdy pojazdu szynowego, Prace Naukowe Transport, z.63, str. 125-132, Oficyna Wydawnicza Politechniki Warszawskiej, Warszawa 2007

[14] Kardas-Cinal E., Droździel J., Sowiński B.: Simulation testing of a relation between the derailment coefficient and the track condition, Archives of Transport, Vol. 21, issue 1-2, 2009, pp.85-98,

[15] Kardas-Cinal E.: Comparative study of running safety and ride comfort of railway vehicle, Prace Naukowe Transport, Zeszyt 71, Oficyna Wydawnicza Politechniki Warszawskiej, Warszawa 2009, str.7584

[16] Kardas-Cinal E.: Spectral analysis of derailment coefficient in railway vehicle - track system with random track irregularities, Proceedings (on CD) of 21st International Symposium on Dynamics of Vehicles on Roads and Tracks. IAVSD'09, Stockholm, 2009

[17] Matsudaira, T.: Dynamics of High Speed Rolling Stock, JNR RTRI Quarterly Reports, Special Issue, 1963

[18] M1001, AAR Mechanical Division, Manual of Standards and Recommended Practices, Section CPart II, Volume 1, Chapter XI, Section 11. 5.2 TrackWorthiness Criteria, Revised 199.

[19] Matej J.: Modelowanie oraz symulacyjne badania wagonów bimodalnych $w$ kategoriach zagrożenia wykolejeniem, Prace Naukowe Mechanika z. 234. Oficyna Wyd. Politechniki Warszawskiej, Warszawa 2010

[20] Nadal M. J.: Theorie de la Stabilite des Locomotives, Part 2, Movement de Lacet, Annales des Mines, Vol. 10, 232 (1896).

[21] Piotrowski J.: Poprzeczne oddziatywanie między pojazdem szynowym a torem. Prace Naukowe Mechanika z. 118. Oficyna Wydawnicza Politechniki Warszawskiej, Warszawa 1990.

[22] Shabana A., Zaazaa K., Sugiyama H.,: Railroad Vehicle Dynamics: A Comput. Approach, CRC Press, 2007.

[23] Sobaś M.: Stan $i$ doskonalenie kryteriów bezpieczeństwa przed wykolejeniem pojazdów szynowych (1), Pojazdy Szynowe nr 4, 200. 
[24]UIC Code 518 OR: Testing and approval of railway vehicles from the point of view of their dynamic behaviour - Safety - Track fatigue-Ride quality, International Union of Railways, 2nd edition, April 2003

[25]Weinstock H.: Wheel Climb Derailment Criteria for Evaluation of Rail Vehicle Safety, Paper no. 84WA/RT-1, 1984 ASME Winter Annual Meeting, New Orleans, LA, November 1984

[26]Wu H., Wilson N.: Railway Vehicle Derailment and Prevention, pp. 209-237, in [8]
[27]Wu H., Shu X., Wilson N.: TCRP Report 71, TrackRelated Research, Volume 5: Flange Climb Derailment Criteria and Wheel/Rail Profile Management and Maintenance Guidelines for Transit Operations, Transportation Research Board of the National Academies (USA), 2005

[28]Zboiński K.: Metodyka modelowania dynamiki pojazdów szynowych z uwzględnieniem zadanego ruchu unoszenia $i$ jej zastosowania, Prace Naukowe Transport, z. 43, Oficyna Wydawnicza Politechniki Warszawskiej, Warszawa 2000

[29]Zeng J. and Guan Q. H.: Study on flange climb derailment criteria of a railway wheelset, Vehicle System Dynamics, Vol. 46, No.3, March 2008, pp. 239251 